\title{
CONGENITAL HEREDITARY VERTICAL NYSTAGMUS
}

\author{
BY \\ W. I. FORSYTHE \\ From the Nuffield Department of Child Health of the Queen's University of Belfast and the \\ Royal Belfast Hospital for Sick Children
}

Duke-Elder (1949) states that congenital nystagmus varies considerably in extent, direction, and rapidity of the movements. In most cases it affects both eyes equally, but in a few instances it is uniocular. Typically the movements are pendular in type, horizontal in direction, and do not alter on lateral deviation, although they may then become jerky in type. Sometimes the movement is coarser to one side than the other, in which case the head is habitually turned to place the eyes in the position at which the nystagmus is least. In 1911, Nettleship reviewed nine pedigrees of congenital hereditary nystagmus and to this he added four more which he had examined personally. Hemmes (1926) published a pedigree and reviewed all published pedigrees up to 1924,38 in all. Since then Yawger (1917), Cox (1936), Glover (1937), Waggoner and Boyd (1942), and Rucker (1946) have added their contributions. A careful study of the published reports has shown, with two exceptions, that the nystagmus has been bilateral and horizontal in all cases. Posey (1902) described a native boy, aged 8 years, who had bilateral vertical nystagmus. The time of onset was not known, but oscillations of the head, of a rotary type, began at 5 years. Three siblings were normal and there was no family history of abnormal eye movements. Walsh (1947) states that the nystagmus is usually horizontal, although torsional nystagmus has been observed by Ohm (1938). It would appear, therefore, that congenital nystagmus of the vertical type is rare. This condition is of great interest to the geneticist and it is for this reason that these cases are recorded.

The family described here is of pure Italian extraction and the nystagmus involves five cases spread over three generations; three males and two females. The diagrammatic pedigree is set out in the Appendix. Twelve members of the family have been examined and their blood groups and eye colours, etc., are recorded also in the Appendix. There is no known consanguinity in the matings.

\section{Case Reports}

Case 1 (II 6).-A male aged 67 years had shaking movements of the eyes and head which were thought to have begun at 3 years of age, following a series of convulsions. The nystagmus is binocular, synchronous, and vertical in type and the movements are coarse and pendular. Approximately 70 oscillations occur per minute. This rate is unaffected by fixing or looking to either side. Visual acuity is normal. The oscillatory movements of the head were absent at the first three examinations, but at the fourth the movements were rotary in type, and could be controlled voluntarily. The number of oscillations varied from 20 to 40 per minute. During fixation they tend to diminish in frequency and increased when the patient was not concentrating.

Case 2 (III 7).-In a male aged 38 years nystagmus and head movements were noticed shortly after birth. On examination, the nystagmus and head movements have the same features as Case 1 . Visual acuity is normal. This patient says he can see the eyes shaking in Cases 4 and 5 but not in Cases 1 or 3. He has no difficulty in observing the head movements in the other cases.

Case 3 (IV 10).-In a female aged 15 years nystagmus has been noticed since birth. Head movements started early in infancy and disappeared at 8 years. The nystagmus is binocular, synchronous, and vertical with an approximate rate of 140 to 160 oscillations per minute. The movements are pendular and of moderate amplitude. Visual acuity is normal and there are no errors of refraction. This patient could see the eyes shaking in Cases 1 and 4 but is unable to appreciate this in Cases 2 and 5. Head movements are easily observed. The position of the head is normal.

Case 4 (IV 13). - In a male aged 10 years nystagmus and head movements were noticed since birth. The nystagmus is similar to Case 3, except that the rate is approximately 130 oscillations per minute. Vision is normal and there are no errors of refraction. Rotary oscillations of the head have been observed on several occasions. They are not present all the time and tend to diminish during fixation. When he is not fixing, the oscillations start at a slow rate, approximately 5 to 7 per minute and gradually increase to 30 to 40 per minute. The patient is conscious of these movements and can 
stop them in a short time. The head movements disappear during sleep, but the nystagmus persists. It was observed that the head movements cease when the eyes are closed. The patient keeps his head habitually rotated to the right and the occiput slightly depressed towards the left shoulder, so that his eyes are directed somewhat to the left and upwards. The patient is left-handed and his Stanford-Binet I.Q. is 80. This patient was subjected to caloric tests as described by Fitzgerald and Hallpike (1942) in order to determine the function of the labyrinth, but there was no response to these tests.

Case 5 (IV 15). - In a female aged 15 months nystagmus was noticed at birth. The nystagmus is binocular, synchronous, and vertical in type, and the movements are pendular and of very wide range. Approximately 60 oscillations occur per minute. The rate is unaffected by fixing or looking to the side. The nystagmus is unaltered during sleep and there are no errors of refraction in either eye. Up to the present, no abnormal head movements have been observed.

\section{Discussion}

Nettleship drew attention to the fact that there seemed to be an association between the head movements and mode of descent in hereditary nystagmus. In some stocks the disease was transmitted by either sex, and affected females almost as frequently as males. This type was frequently associated with oscillation of the head. In another group the nystagmus was limited to males but was directly transmitted only by females and this suggested a sex-linked recessive factor. Oscillations of the head were rare or absent in this group. Glover (1937) described a family in which only males showed the defect and several had head nodding which tended to disappear. Rucker (1946) showed in his pedigree that the nystagmus was inherited as a sex-linked recessive factor and a considerable number of the affected persons had associated head movements. Duke-Elder (1949) subdivides congenital nystagmus into three groups : (a) An ambi-sexual irregularly dominant form, affecting both sexes, but males more frequently than females ; frequently there are associated head movements. (b) A recessive sex-linked type, which is limited to males; head movements are not common, but defects in the eyes such as pigmentary failure, red-green colour blindness, and in the central nervous system, e.g., Lebers optic atrophy or spastic paralysis. (c) A simple recessive rare form, which is frequently associated with consanguinity in the parentage. The pedigree described in this paper would be acceptable in the first group, except for the vertical nystagmus. It is not possible to draw any conclusions from such a small number of cases, but it would appear that the type of nystagmus is not tied to a particular mode of inheritance. Nettleship (1911), Cox (1936), and Walsh (1947) observed that the nystagmus was less marked during fixation and was increased by looking sideways. In this pedigree fixation and alteration of the visual axis had no effect on the nystagmus. It is interesting that some of these patients were unable to appreciate the nystagmus in others. It was thought at first that the eyes must be synchronizing, but in Cases 2 and 3 this does not seem possible as there was a considerable difference in the rate and amplitude of the nystagmus. Nettleship described a baby with rotary head movements, who died at 5 months of age. The sister, herself affected, was able to recall the head movements, but could not say whether or not the eyes were involved. It is possible that this girl could not appreciate the abnormal eye movements in her brother, and it is therefore important to obtain histories from unaffected members of the family, otherwise several cases may be missed.

Cox was of the opinion that the head movements cancelled the nystagmus in order to steady the retinal image, and refers to Nettleship as having made the same observation. This, however, is not necessarily correct, for according to Nettleship :

"So far as I have been able to observe, the two movements, when both are present, are in the same plane, both as a rule being horizontal. But whether the rapidity of the head-and-eye movements is the same and their rhythm such that one tends to neutralize the other I cannot say, and I doubt whether accurate information on the point can be gathered unless instantaneous photography or some kind of automatic movement-recorder can be pressed into the service."

In this pedigree and the case described by Posey (1902) the head movements were not in the same plane as the nystagmus, their rate was much slower, and the fact that the movements disappeared makes it difficult to imagine that the head movements were neutralizing or compensating for the nystagmus. M'Gillivray (1895) describes a patient with horizontal nystagmus and head movements, in which the head movements started with a nod, then rotation to the left, and this was followed by an upward movement with the result that the head movements roughly described a circle. In the other five cases the nystagmus was more rapid than the rotary head movements. M'Gillivray observed that the head movements were more active during fixation and Nettleship and Cox observed this in some of their cases. In this series the movements diminished during fixation and increased whilst gazing abstractedly. Case 2 volunteered the information that he was more conscious of the head movements while concentrating and he tried to suppress them as soon as they appeared. 
The actual site of the lesion in congenital hereditary nystagmus is unknown as none of the cases have come to post-mortem study. Peripheral failure of fixation was suggested as an aetiological factor, but this could only apply if the nystagmus began after the first month, i.e., when the normal infant begins to fix. Nettleship (1911) describes cases where the nystagmus was present at birth and to this may be added Cases 4 and 5. Posey (1902) discussed his case with Professor W. G. Spiller (Philadelphia), who suggests that the vertical nystagmus might be due to weakness in the ocular muscles and that the lateral head movement might be due to slight left sterno-cleido-mastoid muscle weakness. Yawger (1917) referred his case to Dr. Alexander Bruce (Philadelphia), who suggested that Deiter's nucleus might be the site of the lesion. Nettleship (1911) suggests that there may be a congenital lack of pigmentation of the retinal epithelium in the region of the macula. Walsh (1947) observed several negro families with hereditary nystagmus where pigmentation could scarcely be a factor. Hemmes (1926) thought that the nystagmus was due to a disturbance of the function of the otoliths. Duke-Elder (1949) thinks that anomalies may exist in the vestibular tracts and centres, or in the connexions between these centres and the oculo-motor nuclei, as well as a disturbance in the labyrinthine mechanism. It is impossible to say whether or not the labyrinths are normal in these cases, but Case 4 did not respond to the caloric tests. An unaffected member of the family gave a normal response.

\section{Summary}

Five cases of congenital hereditary nystagmus have been described. They are unusual in that the nystagmus was vertical in all, and in three patients the head movements were rotary in type. Linkage data are presented.

I would like to thank Professor F. M. B. Allen for permission to study these cases and Professor A. C. Stevenson for his helpful advice and criticism.

\section{REFERENCES}

Cox, R. A. (1936). Arch. Ophthal., Chicago, 15, 1032.

Duke-Elder, W. S. (1949). Text-book of Ophthalmology, vol. 4, p. 4234. Kimpton, London.

Fitzgerald, G., and Hallpike, C. S. (1942). Brain, 65, 115.

Glover, L. P. (1937). Arch Ophthal., Chicago, 17, 705.

Hemmes, G. D. (1926). Brit. J. Opthal., 10, 48.

M'Gillivray, A. (1895). Ophthal. Rev., 14, 252.

Nettleship, E. (1911). Trans. ophthal. Soc. U.K., 31, 159.

Ohm, J. (1938). v. Graefes Arch. Ophthal., 138, 693.

Posey, W. C. (1902). J. Amer. med. Ass., 39, 1365.

Rucker, C. W. (1946). Amer. J. Ophthal., $29,1534$.

Waggoner, R. W., and Boyd, D. A. (1942). Ibid., 25, 177.

Waggoner, R. W., and Boyd, D. A. (1942). Mid., 25, 177.

Walsh, F. B. (1947). Clinical Neuro-Ophthalmology, p. 320. Williams and Wilkins, Baltimore.

Yawger, N. S. (1917). J. Amer. med. Ass., 69, 773.

A P P E N D I X

\section{VERTICAL NYSTAGMUS}

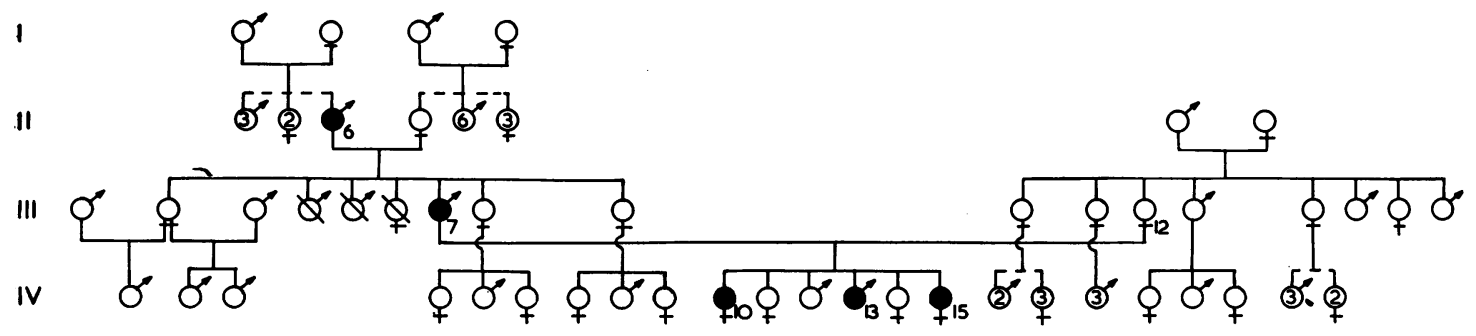

LINKAGE DATA

\begin{tabular}{|c|c|c|c|c|c|c|c|c|c|c|c|c|c|}
\hline $\begin{array}{l}\text { Chart } \\
\text { Ref. }\end{array}$ & $\begin{array}{l}\text { Birth } \\
\text { Date }\end{array}$ & Sex & Seen & Affected & Taste & $\begin{array}{l}\text { Colour } \\
\text { Vision }\end{array}$ & ABO & M. & N. & S. & Rh & P. & $\begin{array}{c}\text { Eye } \\
\text { Colour }\end{array}$ \\
\hline $\begin{array}{ll}\text { II } & 6 \\
\text { II } & 7 \\
\text { III } & 2 \\
\text { III } & 7 \\
\text { III } & 8 \\
\text { III } & 9 \\
\text { III } & 12\end{array}$ & $\begin{array}{l}1887 \\
1894 \\
1911 \\
1916 \\
1917 \\
1918 \\
1915\end{array}$ & $\begin{array}{l}\mathbf{M} \\
\mathbf{F} \\
\mathbf{F} \\
\mathbf{M} \\
\mathbf{F} \\
\mathbf{F} \\
\mathbf{F}\end{array}$ & $\begin{array}{l}\text { Yes } \\
\text { Yes } \\
\text { Yes } \\
\text { Yes } \\
\text { Yes } \\
\text { Yes } \\
\text { Yes }\end{array}$ & $\begin{array}{l}\text { Yes } \\
\text { No } \\
\text { No } \\
\text { Yes } \\
\text { No } \\
\text { No } \\
\text { No }\end{array}$ & $\begin{array}{l} \pm \\
\pm \\
= \\
+ \\
\pm \\
+\end{array}$ & $\begin{array}{l}+ \\
+ \\
+ \\
+ \\
+ \\
+\end{array}$ & $\begin{array}{l}\mathbf{A}_{1} \\
\mathbf{A}_{1} \\
\mathbf{A}_{1} \\
\mathbf{A}_{1} \\
\mathbf{A}_{1} \\
\mathbf{A}_{1} \\
0\end{array}$ & $\begin{array}{l}- \\
+ \\
+ \\
+ \\
+ \\
+ \\
-\end{array}$ & $\begin{array}{l}+ \\
+ \\
+ \\
+ \\
+ \\
+ \\
+\end{array}$ & $\begin{array}{l}+ \\
+ \\
+ \\
+ \\
+\end{array}$ & $\begin{array}{l}R_{0} r \\
R_{1} R_{1} \\
R_{1} R_{0} \\
R_{1} R_{0} \\
R_{1} R_{0} \\
R_{1} R_{0} \\
R_{1} R_{1}\end{array}$ & $\begin{array}{l}+ \\
+ \\
+ \\
+ \\
+ \\
+ \\
+\end{array}$ & $\begin{array}{l}\text { Blue } \\
\text { Brown } \\
\text { Brown } \\
\text { Brown } \\
\text { Brown } \\
\text { Brown } \\
\text { Brown }\end{array}$ \\
\hline $\begin{array}{ll}\text { IV } & 10 \\
\text { IV } & 11 \\
\text { IV } & 12 \\
\text { IV } & 13 \\
\text { IV } & 14 \\
\text { IV } & 15\end{array}$ & $\begin{array}{c}5.4 .39 \\
1941 \\
3.2 .43 \\
1.5 .44 \\
23.12 .48 \\
24.8 .53\end{array}$ & $\begin{array}{l}\mathbf{F} \\
\mathbf{M} \\
\mathbf{M} \\
\mathbf{F} \\
\mathbf{F}\end{array}$ & $\begin{array}{l}\text { Yes } \\
\text { No } \\
\text { Yes } \\
\text { Yes } \\
\text { Yes } \\
\text { Yes }\end{array}$ & $\begin{array}{l}\text { Yes } \\
\text { No } \\
\text { No } \\
\text { Yes } \\
\text { No } \\
\text { Yes }\end{array}$ & $\begin{array}{l}\overline{-} \\
\overline{-} \\
\overline{-} \\
?\end{array}$ & $\begin{array}{l}+ \\
+ \\
+ \\
+ \\
+ \\
?\end{array}$ & $\begin{array}{l}0 \\
\mathbf{A}_{1} \\
0 \\
\mathbf{A}_{1}\end{array}$ & $\begin{array}{c}- \\
\overline{-} \\
\text { Refused }\end{array}$ & $\begin{array}{c}+ \\
+ \\
+ \\
+ \\
+\end{array}$ & $\begin{array}{c:c}- & \\
+ & \\
+ & \\
\text { ination } & \\
+ & \end{array}$ & $\begin{array}{l}\mathbf{R}_{\mathbf{1}} \mathbf{R}_{\mathbf{1}} \\
\mathbf{R}_{\mathbf{1}} \mathbf{R}_{\mathbf{1}} \\
\mathbf{R}_{\mathbf{1}} \mathbf{R}_{\mathbf{0}} \\
\mathbf{R}_{\mathbf{1}} \mathbf{R}_{\mathbf{1}}\end{array}$ & $\begin{array}{l}+ \\
- \\
-\end{array}$ & $\begin{array}{l}\text { Brown } \\
\text { Blue } \\
\text { Blue } \\
\text { Brown } \\
\text { Blue } \\
\text { Blue }\end{array}$ \\
\hline
\end{tabular}

